\title{
Vulnerabilidade na adolescência com enfoque em infecções sexualmente transmissíveis e os desafios dos professores no processo de orientação
}

\author{
Danielle Ribeiro Rocha* \\ Gabriele Marisco da Silva**
}

\section{Resumo}

As mudanças que ocorrem na adolescência tornam os adolescentes vulneráveis a situações de risco, como a possibilidade de contrair Infecções Sexualmente Transmissíveis (ISTs). Nesse sentido, objetivou-se identificar fatores que contribuem para a vulnerabilidade na adolescência com enfoque em ISTs e os desafios da orientação pelos docentes em educação em saúde, por meio da perspectiva da comunidade escolar da zona rural de Vitória da Conquista-Bahia. Foram aplicados questionários e são considerados fatores de vulnerabilidade as fontes inadequadas de informações e a falta de orientação, sendo necessárias estratégias educativas para atender e sensibilizar a comunidade escolar sobre educação em saúde e ISTs de forma continuada.

Palavras-chave: Educação em saúde. Capacitação docente. Vulnerabilidade na adolescência.

*daniellerocha_01@hotmail.com

** gabrielemarisco@hotmail.com 


\title{
Vulnerability in adolescence with a focus on sexually transmitted infections and the challenges of teachers in the orientation process
}

\begin{abstract}
The changes that occur in adolescence make adolescents vulnerable to situations of risk, such as the possibility of contracting Sexually Transmitted Infections (STIs). In this sense, the objective was to identify factors that contribute to vulnerability in adolescence with a focus on STIs and the challenges of guidance by teachers in health education, through the perspective of the school community in the rural area of Vitória da Conquista-Bahia. Questionnaires were applied and inadequate sources of information and lack of guidance are considered as vulnerability factors, and educational strategies are necessary to attend and sensitize the school community on health education and STIs on an ongoing basis.
\end{abstract}

Keywords: Health education. Teacher training. Vulnerability in adolescence.

\section{Vulnerabilidad en la adolescencia con enfoque en infecciones sexualmente transmisibles y los desa- fíos de los profesores en el proceso de orientación}

\section{Resumen}

Los cambios que se producen en la adolescencia hacen a los adolescentes vulnerables a situaciones de riesgo, como la posibilidad de contraer infecciones de transmisión sexual (ITS). En este sentido, el objetivo fue identificar los factores que contribuyen a la vulnerabilidad en la adolescencia con un enfoque en las ITS y los desafíos de la orientación de los docentes en educación para la salud, a través de la perspectiva de la comunidad escolar en el área rural de Vitória da Conquista-Bahia. Se aplicaron cuestionarios y las fuentes de información inadecuadas y la falta de orientación se consideran factores de vulnerabilidad, y se necesitan estrategias educativas para asistir y sensibilizar a la comunidad escolar sobre la educación para la salud y las ITS de manera continua.

Palabras clave: Educación en salud. Formación de profesores. Vulnerabilidad en la adolescencia. 


\section{Introdução}

A adolescência é um período complexo, marcado por mudanças físicas, psicológicas e comportamentais, principalmente voltadas para a sexualidade, que levam os adolescentes a ter novas experiências, buscar independência e adotar práticas que nem sempre são saudáveis, tornando-os mais vulneráveis a riscos (NAKAGAWA et al., 2010; MARTINS et al., 2013; OLIVEIRA et al., 2018).

A vulnerabilidade é uma característica apresentada por indivíduos com acesso a situações que afetam a cognição, o corpo físico e até mesmo estruturas sociais, tornando-os desprotegidos e frágeis (VILLELA E DORETO, 2006). No Brasil, a vulnerabilidade na adolescência é alta (FONTES et al., 2017) e é marcada por um risco maior de contrair Infecções Sexualmente Transmissíveis (IST), um conjunto de infecções que são transmitidas por microrganismos principalmente pela prática sexual sem métodos de segurança (BASTOS et al., 2008).

Entre as IST de alta incidência há o Papiloma Vírus Humano (HPV), que é transmitido pelo contato direto com o tecido de revestimento infectado (BOETTCHER, 2015; SÃO PAULO, 2013) e pode causar verrugas, lesões de baixo grau no colo do útero, assim como câncer de colo do útero, de vagina e de pênis (ZARDO et al., 2014; LETO et al., 2011).

Pela ocorrência do HPV ser complexa, há uma maior preocupação com crianças, uma vez que a imunização antes da exposição ao vírus resulta em uma proteção eficiente e duradoura (COSTA E GOLDENBERG, 2013; OSIS et al., 2014). Nesse sentido, foram desenvolvidas vacinas para crianças e adolescentes e na rede pública estão disponíveis para a faixa etária de 9 a 13 anos (BRASIL, 2015).

Segundo Boettcher (2015), muitos adolescentes não possuem informações sobre infecções sexuais como o HPV ou recebem informações equivocadas. Ew et al. (2017) relatam que pais e professores apresentam receio ou dificuldade para falar sobre sexualidade e educação sexual, assuntos que são envoltos por tabus e associados de forma errônea com práticas sexuais. Além disso, Oli- 
veira et al. (2018) ressaltam que o profissional da saúde nem sempre está preparado para abordar a temática em espaços escolares.

Outros meios que podem e costumam ser utilizados para obter informações são os meios eletrônicos, pois são de fácil acesso e as pessoas acreditam obter um conhecimento amplo. Entretanto, muitas informações que chegam por meio da tecnologia, principalmente voltadas para a sexualidade, são superficiais e auxiliam na falta de debate da temática, colaborando para situações de risco, como exposição à IST e a intolerância (EW et al., 2017).

Nesse contexto, é importante que os adolescentes tenham acesso a informações seguras sobre sexualidade e que sejam orientados pela escola, família e profissionais da saúde (LOPES E BARBOSA, 2015) e diferentes ferramentas preventivas podem ser utilizadas para diminuir o contágio por IST.

A educação em saúde é um conjunto de práticas pedagógicas associadas com ações educativas (BRASIL, 2006) que podem ser realizadas nas escolas e são eficientes na propagação de informações a respeito de fatores de risco e sobre prevenção (SALCI, 2013).

Além disso, a formação continuada de professores na área de saúde é fundamental para que estes consigam atuar de forma efetiva na orientação de alunos, uma vez que a capacitação permite a ampliação da percepção de saúde e auxilia no bom desenvolvimento de estratégias para trabalhar com a temática em sala de aula (MELLO-CARPES et al., 2012).

Nessa perspectiva, este trabalho objetivou identificar fatores que contribuem para a vulnerabilidade na adolescência relacionada com IST e com enfoque em HPV, bem como, as dificuldades e desafios encontrados pelos professores na orientação com enfoque em educação em saúde.

\section{Metodologia}

Foi realizado um estudo descritivo, do tipo transversal, com abordagem quantitativa e qualitativa. A pesquisa foi realizada em cinco escolas municipais da zona rural de Vitória da Conquis- 
ta-Bahia. Este trabalho foi aprovado pelo comitê de ética sob o número 80137517.2.0000.0055, seguindo as exigências relacionadas ao Termo de Consentimento Livre e Esclarecido (TCLE) e termo de assentimento.

A aplicação dos questionários foi realizada no período de outubro a novembro de 2017. Em um primeiro momento, ocorreu a visita às escolas para apresentar a proposta desta pesquisa e obter permissão para realizar a coleta de dados. No segundo momento, foram entregues para os alunos questionários que deveriam ser encaminhados para os pais, com o objetivo de obter informações acerca do conhecimento sobre IST/HPV, a opinião deles a respeito da abordagem desse assunto na escola, bem como, saber se os filhos são orientados sobre isso em casa.

Em sequência, aconteceu a coleta de dados nas escolas, com alunos de 12 a 19 anos de idade, onde foi aplicado o questionário semiaberto contendo perguntas acerca do conforto para falar sobre IST. Além disso, todos os professores das cinco escolas foram convidados a participar da pesquisa por meio de um questionário contendo perguntas a respeito da abordagem de IST em sala de aula e perguntas para identificar fatores que impedem a abordagem do tema e contribuem para a vulnerabilidade.

\section{Resultados e discussão}

A adolescência é um período em que ocorrem mudanças físicas e comportamentais que envolvem a vivência da sexualidade (NAKAGAWA et al., 2010; MARTINS et al., 2013), sendo marcado por fragilidades e um risco maior de contrair IST (BASTOS et al., 2008). Nesse sentido, foram escolhidos para participar da pesquisa 178 alunos com idade entre 12 a 19 anos.

Ao questionar os alunos sobre onde recorrem para esclarecer dúvidas que surgem a respeito de ISTs, a maioria relatou recorrer a postos de saúde e internet. E destacamos que somente 17,37\% dos alunos obtêm esclarecimentos com os responsáveis e 8,11\% na escola (Figura 1). 
Figura 1: Meios e fontes de esclarecimentos dos alunos sobre ISTs.

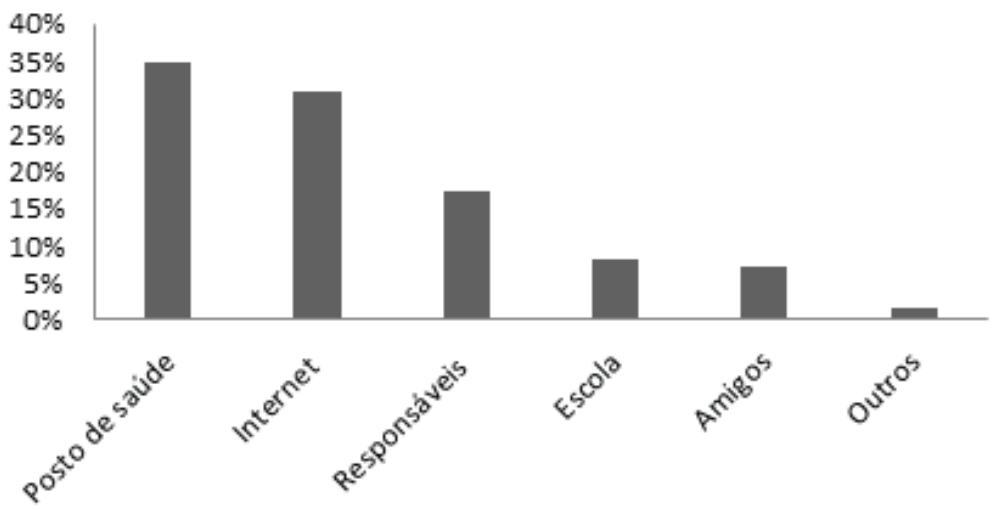

Esses dados obtidos corroboram com Santos et al. (2018), que afirmam ser os postos de saúde e a internet os meios mais recorridos pelos alunos. Fontes et al. (2017) ressaltam que a internet pode garantir níveis significativos de conhecimentos e favorecer práticas saudáveis em relação à IST. Entretanto, Moreira et al. (2015), embora reconheçam que os adolescentes recorram com frequência à internet, destacam que é importante lembrar que há meios mais seguros para obter informações, como o diálogo com os pais e professores, fazendo-se necessário ter uma discussão com os mesmos para ampliar a prevenção de doenças.

Em relação aos postos de saúde, é notável que sejam importantes para a comunidade por atuar em tratamentos, prevenção e ser um ambiente de acesso à informação. Entretanto, como ressaltado por Manoel et al. (2017), entre agentes comunitários de saúde muitas vezes não há muito conhecimento voltado para doenças específicas, como o HPV, sendo necessário que esses profissionais recebam capacitação para conseguir auxiliar a população corretamente.

Vale destacar que apenas 8,11\% dos alunos procuram sanar as suas dúvidas relacionadas à IST na escola (Figura 1), porém, no que se refere a outra pergunta do questionário, $83,71 \%$ dos alunos informaram que gostariam de obter mais informações na escola sobre IST e HPV. Com esses dados, fica evidente o interesse dos alunos e corrobora com outros estudos em que alunos também se 
mostraram entusiasmados com palestras, aulas e discussões que envolvem sexualidade (GOMES, 2012; ROCHA et al., 2017).

Segundo Miranda e Freitas (2015), os ambientes em que as crianças e adolescentes estão inseridos socialmente são fundamentais no processo de construção da sexualidade e da identidade sexual e que, se a experiência em casa e na escola for positiva e a temática for abordada de forma natural, as crianças e adolescentes irão ter mais cuidado com a saúde sexual e irão vivenciar a sexualidade de uma forma consciente e sem culpa.

Dos 178 questionários enviados para os pais dos alunos participantes dessa pesquisa, somente 49 foram devolvidos, sendo que 13 foram descartados em função de inconsistências no preenchimento do questionário. Desse modo, foram analisados 36 questionários preenchidos pelos pais.

A maioria dos pais que aceitaram participar dessa pesquisa acha importante abordar temas relacionados à IST na escola e repassar informações relativas à transmissão da infecção pelo HPV. Porém, apesar de considerar importante a abordagem do tema na escola, cerca de $40,82 \%$ dos pais não orientam os seus filhos sobre IST e não falam abertamente acerca da sexualidade.

Esses dados evidenciam as dificuldades dos pais na orientação dos filhos a respeito de ISTs e sexualidade. Como Gomes (2012) afirma, a orientação pode não ocorrer porque os pais acreditam que a abordagem irá despertar nos filhos um interesse precoce por sexo.

Além disso, é evidente que boa parte dos pais acredita que a escola seja responsável pela abordagem de temáticas voltadas para a educação sexual. Isso é um equívoco e contribui para a vulnerabilidade dos adolescentes, uma vez que, como ressaltado por Lima e Almeida (2010), a educação sexual precisa ser abordada dentro da sala de aula por professores, mas não anula o papel dos pais que são modelos na vida dos filhos e indispensáveis nesse processo de orientação.

Nas cinco escolas envolvidas nessa pesquisa, há um total de 75 professores, destes, 25 aceitaram participar da pesquisa e res- 
ponderam o questionário, 17 se recusaram a responder por não se sentir confortável para falar do assunto ou afirmaram não ser da área e não ter conhecimento sobre o tema, os outros não foram encontrados nas escolas.

Segundo Nery et al. (2015), os obstáculos para falar sobre sexualidade perpassam por fatores culturais, socioeconômicos e religiosos. Para os autores, até mesmo a forma como os professores e os pais vivenciaram a própria sexualidade na fase da adolescência influenciou na falta de conforto para falar a respeito do assunto.

Vale ressaltar que não há uma área específica para falar sobre ISTs, visto que, nos Parâmetros Curriculares Nacionais (PCN), é enfatizado que a sexualidade está vinculada com concepções de diferentes áreas e pode ser trabalhada por professores de qualquer disciplina, não apenas por professores de Ciências, desde que eles tenham um bom relacionamento com os alunos e saibam tratar o assunto de forma respeitosa (BRASIL, 1999).

Munhoz (2017) chamou a atenção para isso ao dizer que por ser um tema transversal, todos os professores devem estar preparados para falar sobre sexualidade no cotidiano escolar, ressaltando que as disciplinas Ciências e Biologia são fundamentais para auxiliar no aprendizado sobre sexualidade, mas sozinhas não englobam todos os aspectos, uma vez que sexualidade não envolve apenas processos físicos e/ou de reprodução.

Dos professores que participaram dessa pesquisa, quase metade (48\%) afirmou que os alunos procuram esclarecer dúvidas em sala de aula sobre sexualidade. Porém, ao questionar a respeito da forma que conduzem essas questões, $53,86 \%$ dos professores asseveraram esclarecer dúvidas na sala aula, 30,76\% não responderam questionamentos acerca do assunto, pois não se sentem confortáveis ou por ser uma responsabilidade que não cabe ao professor, mas aos pais, e 15,38\% falaram sobre o assunto com quem questionou, mas somente após a aula.

No que se refere aos principais fatores que contribuem para a vulnerabilidade na adolescência, para $45 \%$ dos professores a falta 
de informação é o principal fator, seguido da vida sexual precoce (Figura 2).

Figura 2. Fatores indicados pelos professores que contribuem para a vulnerabilidade na adolescência.

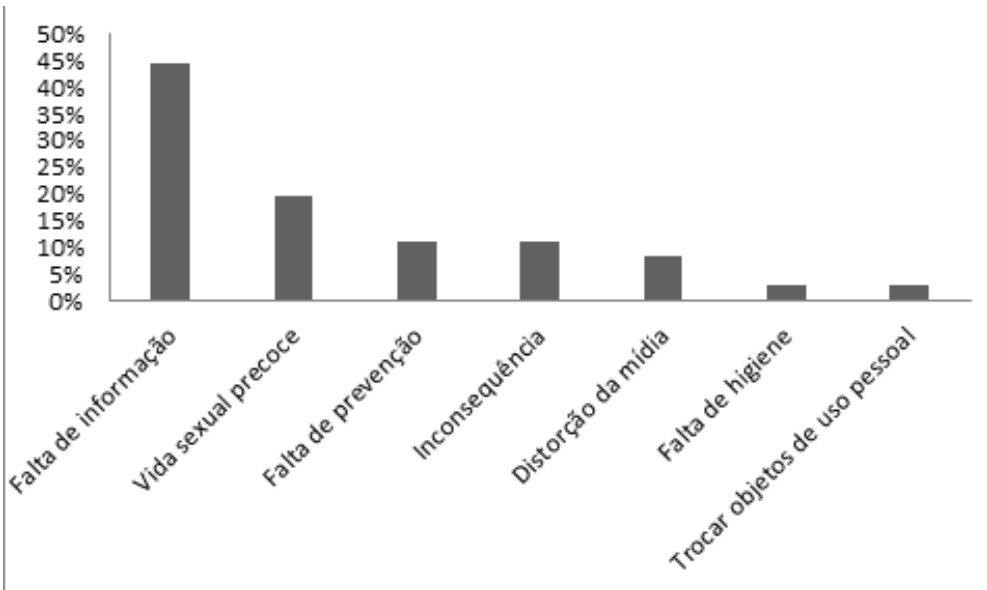

Enquanto os pais, os professores e os profissionais da saúde não abordam a temática por receios, preconceitos, tabus ou até mesmo ideias errôneas acerca da temática, crianças e adolescentes não são orientadas e ficam ainda mais vulneráveis a situações de risco (BARRETO E SANTOS, 2009). É evidente que a responsabilidade é coletiva e é muito importante que os professores não abram mão de falar sobre o assunto, já que a escola é o lugar ideal para que mudanças comecem a ocorrer, como ressaltado nos estudos de Caetano e Silveira (2009).

Para 56,67\% dos professores, é importante abordar temas relacionados com educação em saúde para promover o processo de conscientização dos alunos. Além disso, aumento na qualidade de vida dos alunos, higiene pessoal, educação sexual, direitos assegurados, prevenção e saúde pública também foram citados para justificar a abordagem como indispensável.

$\mathrm{Na}$ resposta do professor de Educação Física (P1), evidencia-se a visão positiva dele em abordar a temática, e a importância 
de a Educação em Saúde ser tratada por todas as disciplinas, não apenas por uma área específica, como pode ser observado a seguir:

Acredito que a falta de informação contribui diretamente para a vulnerabilidade dos jovens. Acredito que devemos focar mais ao tema, não somente na minha disciplina, quanto às outras disciplinas oferecidas no Fundamental II (Professor 01).

Entretanto, a resposta citada é uma exceção, pois, nas respostas da maioria dos professores, é perceptível a resistência em aceitar que a temática deve ser abordada em sala de aula, sendo que aqueles que conseguem assumir a importância da abordagem raras vezes associam isso com um papel coletivo, apenas se limitam a dizer que é para suprir a falta de orientação dos pais:

É muito importante, uma vez que os pais pensam que a escola tem a obrigação de ensinar o letramento e a educação, além de ensinar como cuidar da higiene (Professor 02).

É bastante relevante, já que em sua maioria a família não tem conhecimento ou não sabem orientar os filhos (Professor 03).

Acredito que a informação e conhecimento ainda é a melhor estratégia para diminuir a vulnerabilidade, pois muitos alunos são carentes de uma estrutura familiar que os oriente. A escola acaba por cumprir sozinha uma tarefa que deveria ser coletiva (Professor 04).

A ideia de que o professor não tem obrigação de trabalhar com Educação em saúde precisa ser superada, pois essa responsabilidade é coletiva e não pode continuar cabendo só aos pais, só aos profissionais da saúde, nem mesmo somente aos professores. E como pode ser observado neste estudo, também não há como atribuir toda a responsabilidade para a escola, uma vez que, como ressaltado por Silva (2015), isso é um problema, já que os professores nem sempre conseguem abordar o assunto em sala de aula, seja por vergonha ou por falta de capacitação.

Ao questionar especificamente sobre o HPV, $84 \%$ dos professores afirmam não abordar esse tema em sala de aula. Esse dado 
pode ser justificado por vários fatores, como o receio de repressão dos pais, falta de capacitação e inibição dos professores, que impedem que eles trabalhem com educação sexual (SILVA, 2015).

Quando questionados sobre como diminuir a vulnerabilidade na adolescência, 41\% dos professores acreditam que a orientação seja indispensável para diminuir a vulnerabilidade, 17,24\% acreditam que seja necessário conscientizar a família e 13,79\% acreditam que isso seja possível com campanhas e palestras. Além disso, $3,45 \%$ dos professores acreditam que começar a ter uma boa higiene pessoal já ajuda no processo de conter a vulnerabilidade.

Esses dados mostram como os professores reconhecem a importância da conscientização e se faz necessário estimular a abordagem da educação sexual e sexualidade em sala de aula, que muitas vezes não ocorre por receio de repressão ou por falta de capacitação. Nesse sentido, é necessário oferecer cursos que tornem os professores seguros e capazes de desenvolver metodologias novas e eficientes (SILVA E LIMA, 2013).

Apenas 28\% dos professores afirmaram ter recebido capacitação suficiente para trabalhar com HPV. Esse dado corrobora com a afirmação de Barreto e Santos (2009), segundo a qual há uma limitação no processo de capacitação dos professores em relação à prevenção de IST, que pode ser causada tanto por tabus quanto por uma formação que não atende a assuntos de extrema importância para os adolescentes.

É notório que apesar da sexualidade fazer parte do ser humano e das ISTs estarem cada vez mais incidentes, há uma dificuldade em abordar o assunto, por desconforto e pela visão errônea da sexualidade ligada a práticas sexuais, e isso suscita a importância de uma boa formação inicial e continuada de professores para tratar essa temática (BARRETO E SANTOS, 2009; EW et al., 2017).

Apenas 16\% dos professores abordam HPV em suas aulas e afirmaram que a metodologia utilizada são aulas expositivas. Rocha et al. (2017) ressaltam que, apesar dessa metodologia ser a mais frequente no ensino de IST, não é atraente para os alunos, uma 
vez que eles não prestam muita atenção e não conseguem filtrar as informações necessárias, fazendo-se necessário desenvolver novas estratégias para que fiquem menos dispersos e consigam compreender de fato o que está sendo ensinado.

Nesse mesmo sentido, Rolt (2014) afirma que as metodologias participativas são estratégias eficientes, motivadoras e menos cansativas, além de tornar o aluno o sujeito da aprendizagem ao fazer que ele não fique apenas sentado ouvindo determinado conteúdo.

\section{Considerações finais}

A partir de dados apontados por alunos, professores e pais, foi possível identificar que os principais fatores que contribuem para a vulnerabilidade dos adolescentes em relação às ISTs são as fontes inadequadas utilizadas para obter informações sobre o tema, a ausência de orientação por parte dos pais e o desconforto e falta de capacitação dos professores.

É notável o interesse dos adolescentes em receber informações sobre assuntos voltados para a educação sexual. Entretanto, ficou evidente que poucos pais orientam seus filhos ou falam abertamente a respeito de sexualidade, mas consideram importante a escola falar de ISTs.

Neste estudo, foi possível identificar que os professores são procurados para esclarecimentos, porém a maioria possui insegurança para orientar sobre esses assuntos, pois consideram que não possuem formação específica para abordar o assunto ou apresentam resistência. Até mesmo a recusa em participar da pesquisa por não se sentir confortável para falar acerca de questões que envolvem sexualidade, educação sexual e ISTs, mostra como fatores culturais, individuais e de formação influenciam na abordagem e como os professores, que também são protagonistas no processo de conscientização, se posicionam diante de questões que podem colaborar para a vulnerabilidade na adolescência.

Destaca-se a necessidade de desenvolvimento de estratégias educativas na comunidade escolar, não apenas para sensibilizar ado- 
lescentes, mas também para sensibilizar pais e professores a discutir sobre ISTs. Essas estratégias, envolvendo a família, os profissionais da saúde e da educação, provavelmente poderão contribuir para o desenvolvimento de um bom trabalho voltado para a educação em saúde, diminuindo a vulnerabilidade desses adolescentes.

Existem muitos desafios para superar os preconceitos e dificuldades em abordar temas relacionados à educação sexual, porém educadores, pais, e profissionais da saúde precisam investir nessa abordagem para a prevenção de doenças e aumento de conscientização entre os adolescentes.

\section{Referências}

BARRETO, A. C. M.; SANTOS, R. S. A vulnerabilidade da adolescente às DST: contribuições para a prática da enfermagem. Esc. Anna Nery Rev. Enferm., v. 13, n. 4, p. 809-816, 2009. Disponível em: <http://www.scielo.br/pdf/ean/v13n4/ v13n4a17>. Acesso em: 13 out. 2017 às $11 \mathrm{~h}$.

BASTOS, F. I.; CUNHA, B. C.; HACKER, M. A. Sinais e sintomas associados às doenças sexualmente transmissíveis no Brasil, 2005. Rev. Saúde Pública, v. 42, n. 1, p. 98-108, 2008. Disponível em: https://www.scielosp.org/pdf/rsp/2008. v42suppl1/98-108/pt. Acesso em: 26 jun. 2019 às $01 \mathrm{~h} 27$.

BOETTCHER, C. L. Representações Sociais de Adolescentes sobre o Papiloma Vírus Humano, 2015. Dissertação (Mestrado em Ciências da Saúde) - Universidade Federal de Pelotas, Pelotas, RS, 2015. Disponível em: http://wp.ufpel. edu.br/pgenfermagem/files/2016/02/Disserta \%C3\%A7\%C3\%A3o-Cassia-Boettcher.pdf. Acesso em: 5 set. 2017 às 19 h05.

BRASIL. Ministério da Saúde. Escolas promotoras de saúde: experiências do Brasil. Brasília, 2006. Disponível em: http://bvsms.saude.gov.br/bvs/publicacoes/escolas_promotoras_saude_experiencias_brasil_p1.pdf. Acesso em: 20 set. 2017 às 20 h15.

BRASIL. Ministério da Educação. Parâmetros Curriculares Nacional: Orientação sexual. Brasília, 1999. Disponível em: http://portal.mec.gov.br/seb/arquivos/ pdf/orientacao.pdf. Acesso em: 15 out. 2017 às $12 \mathrm{~h} 50$.

BRASIL. Ministério da Saúde; Secretaria de Vigilância em Saúde; Departamento de Vigilância de Doenças Transmissíveis; Coordenação-Geral do Programa Nacional de Imunização. Informe Técnico Da Vacina Papilomavírus, Humano 
6,11,16 E 18 (Recombinante). Brasília, fev. 2015. Disponível em: http://www. soperj.org.br/imagebank/Informe_Tecnico_Vacina_HPV_2015_FINAL_20_02. pdf Acesso em: 10 set. 2017 às $16 \mathrm{~h} 05$.

CAETANO, J. C. S; SILVEIRA, C. L. P. O ensino de ciências e a educação para a saúde: compreensão da sexualidade e do HPV no terceiro ano do ensino médio. In: Encontro Nacional de Pesquisa Educação em Ciências, 2009. Disponível em: <encurtador.com.br/bjBX3>. Acesso em: 16 dez. 2018 às 21 h47.

COSTA, L. A.; GOLDENBERG, P. Papilomavírus humano (HPV) entre jovens: um sinal de alerta. Saúde soc., v. 22, n. 1, p. 249-261, 2013. Disponível em: http://dx.doi.org/10.1590/S0104-12902013000100022. Acesso em: 13 out. 2017 às $10 \mathrm{~h} 40$.

EW, R. A. S. et al. Diálogos sobre sexualidade na escola: uma intervenção possível. Psicologia em pesquisa - UFJF, v. 11, n. 2, p. 51-60, jul./dez. 2017. Disponível em: <http://pepsic.bvsalud.org/pdf/psipesq/v11n2/07.pdf>. Acesso em: 12 jan. 2019 às $20 \mathrm{~h} 36$.

FONTES, M. B. et al. Fatores determinantes de conhecimentos, atitudes e práticas em DST/Aids e hepatites virais, entre jovens de 18 a 29 anos, no Brasil. Ciência \& Saúde Coletiva, v. 22, n. 4, p. 1.343-1.352, 2017. Disponível em: <http:/ /www. scielo.br/pdf/csc/v22n4/1413-8123-csc-22-04-1343.pdf>. Acesso em: 1º mar. 2019 às $18 \mathrm{~h} 05$.

GOMES, A. P. M. J. Manifestações da Sexualidade no Comportamento dos Adolescentes e a influência da mídia, 2012. Disponível em: www.diaadiaeducacao.pr.gov.br/portals/pde/arquivos/445-4.pdf. Acesso em: 6 mar. 2019 às 09h16.

LETO, M. G. P. et al. Infecção pelo papilomavírus humano: etiopatogenia, biologia molecular e manifestações clínicas. An Bras Dermatol, v. 86, n. 2, p. 306-17, 2011. Disponível em: www.scielo.br/pdf/abd/v86n2/v86n2a14.pdf. Acesso em: 4 set. 2017 às 09 h16.

LIMA, E.; ALMEIDA, G. B. Educação sexual e práticas pedagógicas. In: IV Colóquio de história - Abordagens interdisciplinares sobre história da sexualidade, nov. 2010. Disponível em: <http://www.unicap.br/coloquiodehistoria/wp-content/uploads/2013/11/4Col-p.723.pdf>. Acesso em: 7 mar. 2019 às 15 h12.

LOPES, A. O. S; BARBOSA, J. A. Vulnerabilidade de Adolescentes de uma Instituição Pública de Ensino ao Vírus da Imunodeficiência Humana. Adolesc. Saude, Rio de Janeiro, v. 12, n. 1, p. 42-49, jan./mar. 2015. Disponível em: http:// adolescenciaesaude.com/audiencia_pdf.asp?aid $2=482 \&$ nomeArquivo $={ }_{\mathrm{v}} 12 \mathrm{n} 1 \mathrm{a} 07$. pdf. Acesso em: 28 mar. 2019 às 18 h05. 
MANOEL, A. L. et al. Avaliação do conhecimento sobre o vírus do papiloma humano (HPV) e sua vacinação entre agentes comunitários de saúde na cidade de Tubarão, Santa Catarina, em 2014. Epidemiol. Serv. Saude, Brasília, v. 26, n. 2, p. 399-404, 2017. Disponível em: www.scielo.br/pdf/ress/v26n2/2237-9622ress-26-02-00399.pdf. Acesso em: 18 jun. 2019 às 17h00.

MARTINS, A. C. N.; MARTINS, A. C. S; FERRAZ, L. M. Papel do enfermeiro na prevenção de infecção por HPV em adolescentes e jovens. In: Convibra, 2013. Disponível em: http://www.convibra.com.br/dwp.asp?id=7858\&ev $=31$. Acesso em: 7 mar. 2019 às 19h12.

MELLO-CARPES, P. B. et al. Formação continuada de professores para promoção da saúde e prevenção de doenças crônicas na escola. Biomotriz, v. 6, n. 2, 2012. Disponível em: <revistaeletronica.unicruz.edu.br/index.php/BIOMOTRIZ/article/viewFile/115/90>. Acesso em: 30 jan. 2019 às 20 h35.

MIRANDA, P. R. M.; FREITAS, F. E. L. Concepções e temas correlatos de sexualidade de alunos do Ensino Fundamental. In: X Encontro Nacional de Pesquisa em Educação em Ciências - X ENPEC, 2015. Disponível em: http:// www.abrapecnet.org.br/enpec/x-enpec/anais2015/resumos/R1232-1.PDF. Acesso em: 2 mar. 2019 às $22 \mathrm{~h} 04$.

MOREIRA, C. B. et al. Acessibilidade dos adolescentes às fontes de informações sobre saúde sexual e reprodutiva. Journal of Human Growth and Development, v. 25, n. 1, p. 50-53, 2015. Disponível em: <pepsic.bvsalud.org/pdf/rbcdh/ v25n1/pt_06.pdf $>$. Acesso em: 3 mar. 2019 às 17 h42.

MUNHOZ, C. Orientação sexual: concepções de futuros professores de biologia, 2017, 34s. Monografia - Universidade Presbiteriana Mackenzie, São Paulo-SP, 2017. Disponível em: https://www.mackenzie.br/fileadmin/OLD/47/Graduacao/CCBS/Cursos/Ciencias_Biologicas/TCC/TCC_1_2017/CAMILA_MUNHOZ.pdf. Acesso em: 08 mar. 2019 às 18 h59.

NAKAGAWA, J. T. T.; SCHIRMER, J.; BARBIERI, M. Vírus HPV e câncer de colo de útero. Rev. bras. enferm., Brasília, v. 63, n. 2, p. 307-11, mar./abr. 2010. Disponível em: < http://www.scielo.br/pdf/reben/v63n2/21.pdf>. Acesso em: 8 set. 2017 às 17 h50.

NERY, I. S. et al. Abordagem da sexualidade no diálogo entre pais e adolescentes. Acta Paul Enferm.; v. 28, n. 3, p. 287-292, 2015. Disponível em: www.scielo. br/pdf/ape/v28n3/1982-0194-ape-28-03-0287.pdf. Acesso em: 28 mar. 2019 às $19 \mathrm{~h} 37$. 
OLIVEIRA, P. S. et al. Vulnerabilidade de adolescentes às doenças sexualmente transmissíveis na atenção primária. Revista de Enfermagem UFPE [on-line], v. 12, n. 3 , p. 753-762, mar. 2018. Disponível em: https://periodicos.ufpe.br/revistas/revistaenfermagem/article/viewFile/25063/28042. Acesso em: 16 nov. 2018 às 22h30.

ROCHA, V. S. et al. Uma abordagem sobre DST'S: Intervenção com jogos didáticos digitais. In: IV Congresso Nacional da Educação - CONEDU, 2017. Disponível em: https://www.editorarealize.com.br/revistas/conedu/trabalhos/ TRABALHO_EV073_MD1_SA16_ID7097_11092017195049.pdf. Acesso em: 12 jan. 2019 às 19 h44.

ROLT, V. A. A utilização de metodologias diferenciadas no ensino de ciências e biologia em duas escolas da rede pública do município de Criciúma. Maiêutica - Curso de Ciências Biológicas, v. 1, n. 1, 2014. Disponível em: https:// publicacao.uniasselvi.com.br/index.php/BID_EaD/article/view/1168/331. Acesso em: 23 out. 2018 às $10 \mathrm{~h} 15$.

SALCI, M. A. et al. Educação em saúde e suas perspectivas teóricas: algumas reflexões. Texto Contexto Enferm. Florianópolis, v. 22, n. 1, p. 224-30, jan./mar. 2013. Disponível em: http://www.scielo.br/pdf/tce/v22n1/pt_27 Acesso em: 9 set. 2017 às $15 \mathrm{~h} 27$.

SANTOS, C. A. et al. Internet e HPV: Uma possibilidade para educação em saúde entre adolescentes? Adolesc Saude, v. 16, n. 1, p. 46-59, 2018. Disponível em: www.adolescenciaesaude.com/detalhe_artigo.asp?id=770. Acesso em: 18 jun. 2019 às $21 \mathrm{~h} 59$.

SÃO PAULO (Estado). Instituto Nacional de Ciência e Tecnologia das doenças do Papilomavírus Humano. Entenda de vez os papilomavírus humanos, as doenças que causam e o que já é possível fazer para evitá-los. Guia do HPV. São Paulo, 2013. Disponível em: http://www.incthpv.org.br/upl/ pdf/130198401720254616_Guia\%20do\%20HPV\%20Julho\%202013.pdf Acesso em: 9 set. 2017 às 16 h09.

SILVA, E. J.; LIMA, G. S. Sexualidade na adolescência: concepções dos alunos do $9^{\circ}$. ano do Ensino Fundamental. In: IX Encontro Nacional de Pesquisa em Educação em Ciências - IX ENPEC, 2013. Disponível em: < http://www.nutes. ufrj.br/abrapec/ixenpec/atas/resumos/R0521-1.pdf>. Acesso em: 2 mar. 2019 às $13 \mathrm{~h} 33$.

SILVA, R. Quando a escola opera na conscientização dos jovens adolescentes no combate às DSTs. Educar em Revista, Curitiba, Brasil, n. 57, p. 221-238, jul./set. 2015. Disponível em: <http://www.scielo.br/pdf/er/n57/1984-0411er-57-00221.pdf>. Acesso em: 8 set. 2017 às 17 h20. 
VILLELA, W. V.; DORETO, T. D. Sobre a experiência sexual dos jovens. Cad. Saúde Pública, v. 22, n. 11, p. 2.467-2.472, nov. 2006. Disponível em: http:// www.scielo.br/pdf/csp/v22n11/21.pdf. Acesso em: 23 dez. 2018 às 18 h58.

ZARDO, G. P. et al. Vacina como agente de imunização contra o HPV. Ciência \& Saúde Coletiva, v. 19, n. 9, p. 3.799-3.808, 2014. Disponível em: http://www. scielo.br/pdf/csc/v19n9/1413-8123-csc-19-09-3799.pdf. Acesso em: 5 set. 2017 às $19 \mathrm{~h} 12$.

Submetido em: 6-9-2019

Aceito em: 13-11-2019 